\author{
Erik Kießling \\ Vorgründungs- und Vorgesellschaften
}

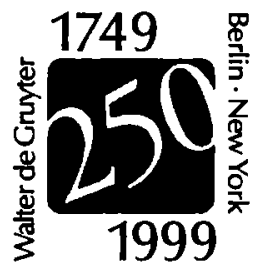





\section{Erik Kießling}

\section{Vorgründungs- und Vorgesellschaften}

$\mathrm{Zu}$ Struktur und Kontinuität der Entstehungsphasen bei AG, GmbH, e. G. und e.V.

$$
\begin{array}{|l|}
\frac{\begin{array}{c}
W \\
D E \\
G
\end{array}}{1999}
\end{array}
$$

Walter de Gruyter · Berlin · New York 
Diese Untersuchung wurde mit dem Forschungsförderpreis der Vereinigung der „Freunde der Universität Mainz e.V.“ ausgezeichnet

Gedruckt mit Unterstützung der Deutschen Forschungsgemeinschaft

D 77

(1) Gedruckt auf säurefreiem Papier, das die US-ANSI-Norm über Haltbarkeit erfüllt.

Die Deutsche Bibliothek - CIP-Einheitsaufnabme

\section{Kießling, Erik:}

Vorgründungs- und Vorgesellschaften : zu Struktur und Kontinuität der Entstehungsphasen bei AG, GmbH, e.G. und e.V. / Erik Kießling. - Berlin; New York : de Gruyter, 1999

Zugl.: Mainz, Univ., Diss., 1998

ISBN 3-11-016460-4

(C) Copyright 1999 by Walter de Gruyter GmbH \& Co. KG, D-10785 Berlin.

Dieses Werk einschließlich aller seiner Teile ist urheberrechtlich geschützt. Jede Verwertung außerhalb der engen Grenzen des Urheberrechtsgesetzes ist ohne Zustimmung des Vetlages unzulässig und strafbar. Das gilt insbesondere für Vervielfältigungen, Übersetzungen, Mikroverfilmungen und die Einspeicherung und Verarbeitung in elektronischen Systemen.

Printed in Germany

Datenkonvertierung: buslau intercom services, 12161 Berlin

Druck und Bindearbeiten: Hubert \& Co., 73079 Görtingen 


\section{Vorwort}

Die vorliegende Untersuchung wurde zum Beginn des Wintersemesters 1998/99 vom Fachbereich Rechts- und Wirtschaftswissenschaften der Johannes Gutenberg-Universität Mainz als Dissertation angenommen. Sie befindet sich im wesentlichen auf dem Stand von August 1998. Später erschienene Literatur konnte nur noch zum Teil und nur in den Fußnoten berücksichtigt werden. Insbesondere blieben die neuesten Überlegungen von Baumann (JZ 1998, S. 598 ff.), der mit einer "Vorgesellschaft in Anwartschaft" den bisher bekannten Dualismus von Vorgründungs- und Vorgesellschaften bei der Gründung von Körperschaften scheinbar um eine dritte Stufe erweitert, unberücksichtigt.

Mein besonderer Dank gilt Herrn Professor Dr. Arndt Teichmann, der die Arbeit betreut und mich, wo immer es nötig wurde, sowohl in fachlicher als auch in persönlicher Hinsicht tatkräftig unterstützt hat. Diese Hilfe beschränkte sich keinesfalls auf die Promotionszeit selbst. Vielmehr griff Herr Professor Teichmann erste, während des Studiums im Rahmen eines Seminars entstandenen Überlegungen zum Gründungsstadium von Körperschaften interessiert auf, er beeinflußte sie mit seiner sehr sachkundigen Kritik maßgeblich und ermutigte mich nach dem Staatsexamen, der Problematik vertieft nachzugehen.

Nicht weniger bin ich Herrn Professor Dr. Walther Hadding verbunden. Dies gilt nicht nur für die von ihm übernommene Zweitkorrektur, sondern vor allem für die fachlich lehrreiche und persönlich sehr angenehme Zeit als wissenschaftlicher Mitarbeiter an seinem Lehrstuhl, in der er mir stets den nötigen Freiraum für die eigene Arbeit ließ und mit seiner ungemein liebenswürdigen Art in so manchen Diskussionen Fehlvorstellungen „zurechtrückte“.

Bedanken möchte ich mich darüber hinaus bei meinen Kollegen Frau Dr. Anja Steinbeck und insbesondere Herrn Dr. Joachim Hennrichs, der mir den Einstieg in das Umwandlungsrecht wesentlich erleichterte und immer wieder die Muße zu klärenden Gesprächen fand. Besonders bedanken möchte ich mich auch bei Frau Sabine Kadel und Herrn Dr. Burkhard Rinne, die die mühevolle Arbeit des Korrekturlesens übernahmen und mir auch sonst als Freunde eine große Hilfe waren.

Der Deutschen Forschungsgemeinschaft und dem „Arbeitskreis Wirtschaft und Recht“ im Stifterverband für die Deutsche Wissenschaft danke ich für die großzügige sachliche Unterstützung bei der Entstehung und dem Druck der Arbeit sowie - in Person von Frau Dr. Dorothee Walther - dem Verlag Walter de Gruyter für die freundliche Aufnahme der Untersuchung in sein Programm.

Die Dissertation wäre ohne die unschätzbare Unterstützung meiner Eltern und vor allem meiner lieben Frau Anke nicht zustande gekommen. Ihnen widme ich die Arbeit. 
